\title{
The CURE for Introductory, Large Enrollment, and Online Courses
}

Kristen S. Genet, Anoka-Ramsey Community College

\begin{abstract}
Increasing undergraduate research opportunities for introductory and non-STEM students benefits large numbers of students from diverse backgrounds. This article assesses a course-based undergraduate research experience (CURE) in a large, introductory course offered both online and in person at an open-door community college. Seated students collaborated during class, and online students collaborated asynchronously at the same pace over eight weeks. Changes in scientific literacy and attitudes toward science varied; seated students showed greater gains and rated their abilities higher upon completion of the CURE. Although online students did show gains, additional interventions improved their experience. This study demonstrates how reflective and iterative evaluation and improvement in CURE integration for introductory courses and non-STEM majors across delivery formats develops best practices for broadening participation in undergraduate research.
\end{abstract}

Keywords: broadening participation, course-based undergraduate research, CURE, curriculum development, online education, undergraduate research

doi: 10.18833/spur/4/3/14

Undergraduate research (UR) is widely accepted as a highimpact education practice that facilitates deep learning and retention (e.g., Bhattacharyya, Chan, and Waraczynski 2018; Laursen et al. 2010; Lopatto 2007; NRC 2003). The benefits of UR for students from a wide variety of backgrounds-including Black, Indigenous, and people of color (BIPOC), as well as underresourced and firstgeneration students-have been well documented and established (e.g., Bhattacharyya, Chan, and Waraczynski
2018; Hunter, Laursen, and Seymour 2006; Seymour et al. 2004), and benefits of UR also extend to faculty (Osborne and Karukstis 2009). Engaging in UR allows students to actively participate in scientific discovery and construct knowledge through experiences. Students participating in research early in their educational programs are allowed to explore ideas and develop passions, which motivates them to succeed as they continue in higher education (e.g., Hartline and Poston 2009).

Traditionally, undergraduate research experiences (UREs) in STEM are geared toward high-achieving students who are majors in those fields and are most often offered in upper level, advanced, and specialty courses. Increasing opportunities and broadening participation in undergraduate research for introductory courses, non-STEM majors, and students who are typically overlooked in STEM allow the benefits of UR to be extended to a far greater number of students (Awong-Taylor et al. 2016; Ballen et al. 2017; Linn et al. 2015). In addition to the often cited benefits of UR for STEM majors (e.g., increased retention, deep learning, increased interest in career path), involving nonSTEM majors who are taking introductory courses also has the potential to increase science literacy, positive attitudes about science, and evidence-based decision-making, which are extremely important regardless of major or intended career path (Ballen et al. 2017). However, large classrooms and online course environments present practical challenges to implementation of UREs in introductory courses and with nonmajors. Involving students from both seated and online course delivery methods will increase understanding and knowledge of the impact of UREs on students interacting with course material in multiple ways. Literature on implementing undergraduate research experiences in an online course delivery environment is 
just emerging, yet with the recent growth and necessity of online course offerings innovative strategies of including online students in UREs need to be developed and piloted. This study fills that gap in current knowledge by providing a comparison between online and seated CUREs as well as evaluating the effectiveness of methods to bring UR into the online environment, particularly for non-STEM major students in introductory courses with large enrollments.

A significant number of students obtaining college degrees enroll in community colleges as they are working to complete degree requirements, and there is great potential for including these students in UREs at community colleges, thereby facilitating student success in transfer to and degree completion at a four-year institution (Cejda 2009; Hensel and Cejda 2014; Higgins et al. 2011). Approximately 50 percent of students completing bachelor's degrees in academic year 2015-2016 had credits transferred from a community college, and in more than 20 states more than half of students earning bachelor's degrees had been enrolled in community colleges during the previous 10 years (NSC Research Center 2017). Community colleges and other two-year institutions traditionally are not well poised to play a significant role in UR, as faculty have demanding teaching schedules, and infrastructure and funding for UR are limited. However, designing, implementing, and sustaining CUREs represents one of the ways that two-year institutions can broaden participation in UR by students at the beginning of their undergraduate education (Hensel and Cejda 2014; Patton and Hause 2020). Embedding research as part of the course curriculum-using research as a way of teaching and learning-provides community college faculty and students opportunities to be engaged with and contribute to the scientific community. Additionally, this study is a significant contribution to current biology education research literature, as only 3 percent of articles published in the last eight years have been authored by community college faculty (Schinske et al. 2017). CUREs have been formally defined as experiences "in which students address a research question or problem that is of interest to the broader community with an outcome that is unknown both to the students and to the instructor" (Auchincloss et al. 2014, 31).

The Scholarship of Teaching and Learning (SoTL) initiative is a faculty learning community centered on teaching and learning across a variety of disciplines and experience. SoTL has a systematic approach to teaching and learning, in which faculty investigate pedagogical questions pertinent to their own practice and classroom experiences, and outcomes are evaluated and shared with others to enhance the teaching experience and students' learning experiences (McKinney 2006). Participation in this faculty network allowed for design and implementation of a pedagogical study to determine the impact of a CURE over a two-year period, as well as collection and evaluation of data on student outcomes, perceptions, and gains in skills and confidence in a large-enrollment, introductory course for non-STEM majors offered in both seated and online delivery formats, using the Undergraduate Research Student Self-Assessment, or URSSA (Weston and Laursen 2015). The ultimate goal was to develop a meaningful and impactful CURE accessible to introductory students that could be integrated into a large (greater than 50 students) introductory course for nonSTEM majors and effective in both seated and online delivery formats. Preliminary work was completed during spring semester 2019, which led to modifications and interventions that were implemented and evaluated during spring semester 2020 (the CURE was completed by midsemester in spring 2020, so it was not affected by the COVID-19 pandemic). The reflective and iterative process of assessment and revision is ongoing and will provide insight into the challenges and strategies of providing an equitable CURE for students to be offered in future terms, including the summer term via an accelerated online format.

\section{CURE Design and Implementation}

This study was conducted at an open-door, two-year public institution that is part of a statewide college and university system. Enrolling more than 12,000 students annually with an average student-to-faculty ratio of 33:1, this institution has two campuses that serve suburban and rural student populations, respectively. Approximately two-thirds of students are under age 25, and 21 percent of students are BIPOC. A variety of UREs are offered in multiple disciplines, both integrated into course curricula and as independent research opportunities mentored by faculty. As a member of the Council on Undergraduate Research, the college adheres to the organization's statement that "faculty members enhance their teaching and contribution to society by remaining active in research and by involving undergraduates in research, and students succeed in their studies and professional advancement through participation in undergraduate research" (CUR n.d.).

The focal course was an introductory environmental science course that introduces basic characteristics and dynamics of ecosystems and explores effects of increasing and changing human demands on the environment. There are no prerequisites for this course, and it fulfills two goal areas within the state transfer curriculum. It is a popular course among students of all backgrounds, abilities, and academic pathways. Multiple sections are offered each term, and several faculty in the Biology Department have experience teaching this course. The course is offered both fully seated and fully online, and the author teaches both content delivery formats. Maximum enrollment for the seated course is 60 students, and each section of the online course has up to 35 students. 
TABLE 1. Summary of Classroom Implementation for WildCam Gorongosa CURE

\begin{tabular}{|c|c|c|}
\hline Week & Task/Assignment & Brief description \\
\hline 1 & $\begin{array}{l}\text { WildCam Gorongosa introduction and } \\
\text { data collection }\end{array}$ & $\begin{array}{l}\text { Students practice identifying African animals from camera trap images and submitting } \\
\text { data on the WildCam Gorongosa platform on Zooniverse. }\end{array}$ \\
\hline 2 & History of Gorongosa National Park & $\begin{array}{l}\text { Students learn about the history and ongoing restoration effort through an online } \\
\text { interactive tool, readings, and videos (HHMI BioInteractive n.d.). }\end{array}$ \\
\hline 3 & $\begin{array}{l}\text { Ecosystems of Gorongosa } \\
\text { National Park }\end{array}$ & $\begin{array}{l}\text { Students explore factors that may influence populations of individual species or entire } \\
\text { communities. They explore potential independent variables and brainstorm about how } \\
\text { those factors influence potential dependent variables. }\end{array}$ \\
\hline 4 & $\begin{array}{l}\text { Scientific inquiry: questions, } \\
\text { hypotheses, predictions, } \\
\text { and variables }\end{array}$ & $\begin{array}{l}\text { Students work collaboratively once they have identified variables to ask an original } \\
\text { question and formulate a hypothesis and prediction that will become the basis of their } \\
\text { research projects. }\end{array}$ \\
\hline 5 & Data analysis: data summaries & Students learn to manipulate spreadsheets with a large amount of data. \\
\hline 6 & Data analysis: figures and tables & $\begin{array}{l}\text { Students use data summaries to produce tables and figures for presentation. Extension: } \\
\text { Students may do inference testing using statistical methods. }\end{array}$ \\
\hline 7 & Data interpretation and conclusions & $\begin{array}{l}\text { Students create a scientific research poster. Patterns in the data are explained using } \\
\text { ecological mechanisms and concepts that are course core content. }\end{array}$ \\
\hline 8 & Peer review of posters & $\begin{array}{l}\text { Students peer review posters from other groups to critically evaluate writing, data } \\
\text { analysis, and visual display. They revise their own posters using peer review comments. }\end{array}$ \\
\hline \multirow[t]{2}{*}{9} & Poster session/ symposium & $\begin{array}{l}\text { In a class poster session or virtual symposium online, student researchers answer } \\
\text { questions from students and faculty. Students submit feedback for other groups' posters } \\
\text { and peer evaluations of group members' contributions to the entire CURE. }\end{array}$ \\
\hline & $\begin{array}{l}\text { College-wide presentation at student } \\
\text { OSCARS event (optional) }\end{array}$ & $\begin{array}{l}\text { Extension: students revise posters based on feedback from the symposium and present } \\
\text { their work at the college-wide Outstanding Scholarship, Creative Activities, and Research } \\
\text { Symposium (OSCARS) recognizing significant student work in all disciplines. }\end{array}$ \\
\hline
\end{tabular}

The embedded CURE uses the WildCam Gorongosa platform (Zooniverse n.d.) and associated resources that are freely available online (HHMI BioInteractive n.d.). Those resources have been significantly modified, and additional classroom activities also were designed. Students work in long-term collaborative groups (four to six students) that are formed and assigned at the beginning of the term. Throughout the first half of the semester, they accomplish tasks each week that guide them through investigating an original research question using the scientific process (see Table 1). Students in the seated section have one dedicated class period of 50 minutes per week ("research day") to work on project tasks. They receive handouts, verbal explanations, demonstrations, and guidance from the instructor during class as they work together in collaborative groups during this class period. Online students work together to complete the same tasks asynchronously each week; these online students receive detailed written instructions with embedded links, and their collaborative space is a discussion forum within the institution's online course learning management system. Upon completion, undergraduate research projects are presented as formal scientific research posters in a classroom symposium: an in-person poster session for the seated course and a virtual symposium for online students. Students also have the opportunity to take peer and faculty feedback and prepare for a college-wide undergraduate research symposium near the end of the semester.

\section{SoTL Design and Methods}

This SoTL project used a cyclical design, evaluation, and redesign method that allowed thoughtful and thorough investigation of the impact of a CURE for introductorylevel undergraduates from the perspectives of improving both teaching and students' learning. The SoTL project was explained to all students, and student participation in the SoTL study was voluntary, although all components of the CURE were required and graded components of the environmental science course.

At the beginning of the term, students completed a preproject survey using the URSSA (Weston and Laursen 2015). The URSSA is a tested and validated web-based survey instrument for evaluating student learning outcomes of UR. The survey questions focus on comfort or confidence with scientific skills and data literacy, as well as attitudes and behaviors associated with scientists and scientific research (survey questions are presented in Table 2). Students then worked through the CURE over the first half of the semester. Upon completion of the CURE, students completed a post-project URSSA. Changes in scientific literacy, attitudes, and behaviors over the duration of the CURE as well as self-assessed proficiency in these areas were then evaluated after the CURE.

Changes in comfort/confidence and abilities/attitudes evaluated in the URSSA were assessed for students 
TABLE 2. Changes in Responses to Pre- and Post-Project URSSA in Spring 2019 and Spring 2020

\begin{tabular}{|c|c|c|c|c|}
\hline & \multicolumn{2}{|c|}{ Spring 2019} & \multicolumn{2}{|c|}{ Spring 2020} \\
\hline & Online $(n=7)$ & Seated $(n=6)$ & Online $(n=11)$ & Seated $(n=21)$ \\
\hline \multicolumn{5}{|l|}{ Thinking and working like a scientist $\mathrm{t}^{\mathrm{a}}$} \\
\hline Figuring out the next step in a research project & 0.14 & $0.83 *$ & 0.55 & 0.29 \\
\hline $\begin{array}{l}\text { Formulating a research question that can be } \\
\text { answered with data }\end{array}$ & 0.29 & $0.83 *$ & 0.36 & 0.43 \\
\hline $\begin{array}{l}\text { Identifying limitations of research methods and } \\
\text { designs }\end{array}$ & 0.57 & 0.50 & 0.55 & $0.62 * * *$ \\
\hline $\begin{array}{l}\text { Understanding the theory and concepts about } \\
\text { population and community ecology }\end{array}$ & 0.29 & $1.33^{*}$ & 0.73 & $0.67 * * *$ \\
\hline $\begin{array}{l}\text { Understanding the connections among scientific } \\
\text { disciplines }\end{array}$ & 0.14 & $1.17 *$ & 0.55 & $0.76^{* *}$ \\
\hline \multicolumn{5}{|l|}{ Personal views related to research ${ }^{\mathrm{a}}$} \\
\hline Confidence in my ability to contribute to science & 0 & $0.83 *$ & 0.27 & 0.14 \\
\hline Comfort in discussing scientific concepts with others & $0.86^{*}$ & 0.83 & 0.73 & 0.05 \\
\hline \multicolumn{5}{|l|}{ Scientific skills and literacy ${ }^{a}$} \\
\hline Making oral presentations & $0.71 * * *$ & $1.00 * *$ & 0.55 & 0.19 \\
\hline Explaining my project to people outside my class & 0.29 & $0.50 *$ & 0.36 & $0.48 * *$ \\
\hline Preparing a scientific poster & 0.86 & $1.67 * *$ & 0.36 & 0.14 \\
\hline Using statistics to analyze data & -0.14 & 0.33 & 0.27 & $0.57 * * *$ \\
\hline Formulating a testable hypothesis and prediction & 0.29 & $0.83 *$ & 0.45 & 0.41 \\
\hline $\begin{array}{l}\text { Organizing, analyzing, and interpreting quantitative } \\
\text { data and scientific information }\end{array}$ & 0.14 & 0.67 & 0.82 & $0.40 *$ \\
\hline Creating graphical representations of data & 0.29 & $0.83 *$ & 0.64 & $0.43 *$ \\
\hline $\begin{array}{l}\text { Reading and interpreting graphical representations } \\
\text { of data }\end{array}$ & 0.29 & 0.33 & 0.55 & $0.76 * * * *$ \\
\hline $\begin{array}{l}\text { Justifying inferences, predictions, and conclusions } \\
\text { based on quantitative data }\end{array}$ & $0.43^{*}$ & $0.83^{*}$ & $0.73 *$ & $0.43 *$ \\
\hline \multicolumn{5}{|l|}{ Research experience and attitudes ${ }^{a}$} \\
\hline Engaging in real-world science research & 0.29 & $0.83 *$ & 0.27 & 0.33 \\
\hline Feeling like a scientist & 0.29 & 0.17 & 0.64 & $0.43 *$ \\
\hline Trying out new ideas or procedures on my own & 0.286 & $0.500 *$ & 0.636 & 0.238 \\
\hline \multicolumn{5}{|l|}{ Future role of scientific research ${ }^{b}$} \\
\hline $\begin{array}{l}\text { Doing research clarified for me which field of study I } \\
\text { want to pursue }\end{array}$ & -1.143 & -0.667 & $-1.091 *$ & 0.286 \\
\hline $\begin{array}{l}\text { My research experience prepared me to transfer from } \\
\text { a two-year to a four-year institution }\end{array}$ & $-1.714 *$ & 0 & -0.727 & 0.571 \\
\hline My research experience prepared me for a job & -0.857 & 0.333 & -0.363 & $0.667^{*}$ \\
\hline \multicolumn{5}{|l|}{ Future education and career plans ${ }^{\mathrm{c}}$} \\
\hline Completing my associate's degree & -0.571 & $-0.500^{*}$ & 0.091 & 0 \\
\hline
\end{tabular}

Note: Student responses were provided on a Likert scale on both pre- and post-project surveys; positive changes indicate gains over the duration of the CURE. Pre- and post-project survey responses were evaluated using a one-tailed paired $t$-test, $\alpha=0.05$. Only survey items with significant change were included. All data are available and can be obtained from the author. URSSA = Undergraduate Research Student Self-Assessment.

${ }^{a}$ How confident or comfortable do you feel about each of the following items (please rate each on a scale from $1=$ very uncomfortable/lack confidence to 5 = very comfortable/confident).

${ }^{b}$ How much do you agree or disagree with the following statements (please rate each item on a scale from $1=$ strongly disagree, $3=$ neutral/no opinion, to $5=$ strongly agree).

${ }^{c}$ How likely do you think you are to (please rate each item on a scale where $1=$ not more likely, $3=$ extremely more likely).

$* p<0.05, * * p<0.01, * * * p<0.005, * * * * p<0.0001$

16 Scholarship and Practice of Undergraduate Research 
who completed both the pre-project survey and postproject survey in spring 2019 (online $n=7$, seated $n=$ 6) and spring 2020 (online $n=11$, seated $n=21$ ) using a one-tailed paired $t$-test $(\alpha=0.05)$. Post-project URSSA responses were evaluated separately for students in spring 2019 (online $n=14$, seated $n=16$ ) and spring 2020 (online $n=23$, seated $n=16$ ) using a two-sample $t$-test $(\alpha=0.05)$. Analysis of outcomes from spring 2019 guided the development and implementation of interventions in spring 2020, with the goal of achieving equitable CUREs for students, independent of course delivery format.

\section{Iterative Evaluation}

In spring 2019, changes in scientific literacy, attitudes toward science and research, and evidence-based decisionmaking varied between treatment groups, with seated students generally showing greater gains in literacy (see Table 2) and rating their abilities and confidence after project completion higher in several different areas evaluated by the URSSA (see Figure 1A). Although online students did learn and gain confidence and proficiency over the duration of the CURE, there were clear disparities, and additional interventions needed to be implemented to make the CURE equitable for online students. Instructor demonstrations, in-person assistance, and synchronous student collaboration are very important in the research process, and those components were not well represented in the online section in spring 2019. As a result of student comments and reflection on the differences seen in spring 2019, it became clear that components that increased both individual engagement and group collaboration were lacking in the online environment, hindering the ability of online students to actively understand and participate in the steps of the scientific process. The interventions that were subsequently developed and implemented included video tutorials, synchronous instructor demonstrations, and group conferences. These tools were implemented in the online section for spring 2020. Although gains in scientific literacy, attitudes toward science and research, and evidence-based decision-making still varied and were more prevalent for seated than online students in spring 2020 (see Table 2), the significant differences in post-project self-assessment seen between the two groups in spring 2019 were not evident in spring 2020, after the additional interventions were implemented for the online group (see Figure 1B). Although significant changes in pre- and post-project assessment scores are valuable for informing decisions about interventions to enhance students' experiences, student participation in the surveys was voluntary and resulted in a small sample size. Additional, more comprehensive evaluations of students' experiences in CUREs in both online and seated courses will be conducted in future semesters.

\section{Impact}

The overall goal of this project was to provide an impactful and meaningful CURE for a large and diverse group of students enrolled in an introductory biology course for mostly non-STEM majors and for the CURE to be accessible and equitable for students, whether they elected to enroll in a seated or online section of the course. Providing a CURE is different from more individual-based mentored UR (e.g., Auchincloss et al. 2014), and although the scope of research is limited due to time constraints and the range of student backgrounds, the benefits for providing these opportunities significantly outweigh the challenges in planning and implementation of the CURE (e.g., Alkaher and Dolan 2014; Corwin, Graham, and Dolan 2015). Broadening participation in UR can increase mentoring and collaboration opportunities, promote students' identities as scientists and researchers, reinforce science as a process, and increase students' conceptual understanding and communication of science. Expansion of UR opportunities to introductory courses and two-year colleges will result in a much greater number of students learning crucial critical thinking and scientific process skills earlier in their educational programs, which will build their confidence and set them up for long-term success as they pursue their degrees and careers (Brandt and Hayes 2012).

The process of designing a highly scaffolded CURE that is accessible to introductory students in both online and seated courses is challenging; however, it offers tremendous potential for increased student engagement and success (Grabowski, Heely, and Brindley 2008). Introductory students benefited from working collaboratively in long-term groups; after the first iteration and assessment in spring 2019, the importance of the verbal explanations, demonstrations, and synchronous discussions to the success of the CURE and student achievement became clear. Overall, both seated and online students worked through the CURE using similar protocols with the same goals and benefits inherent in the scientific process but differed in their means of collaboration. Online students consistently reported communication as a challenge during spring 2019. Students found working asynchronously difficult, identified scheduling conflicts as obstacles, and recognized the value of synchronous collaboration.

Providing opportunities for all students both to listen to and watch instructor explanations and demonstrations (either live or recorded) and to collaborate synchronously with other students were important components for reducing disparities in students' post-project URSSA responses. Communication in an online environment continues to be a challenge, yet providing opportunities and structure for collaborative spaces and synchronous discussions helped students feel connected and successful. After these interventions were implemented, students were more positive about communication and collaborative work and recognized positive outcomes of the CURE. 
FIGURE 1. Mean ( \pm Standard Error) Post-Project URSSA Responses for CURE Implemented in (A) Spring 2019 and (B) Spring 2020

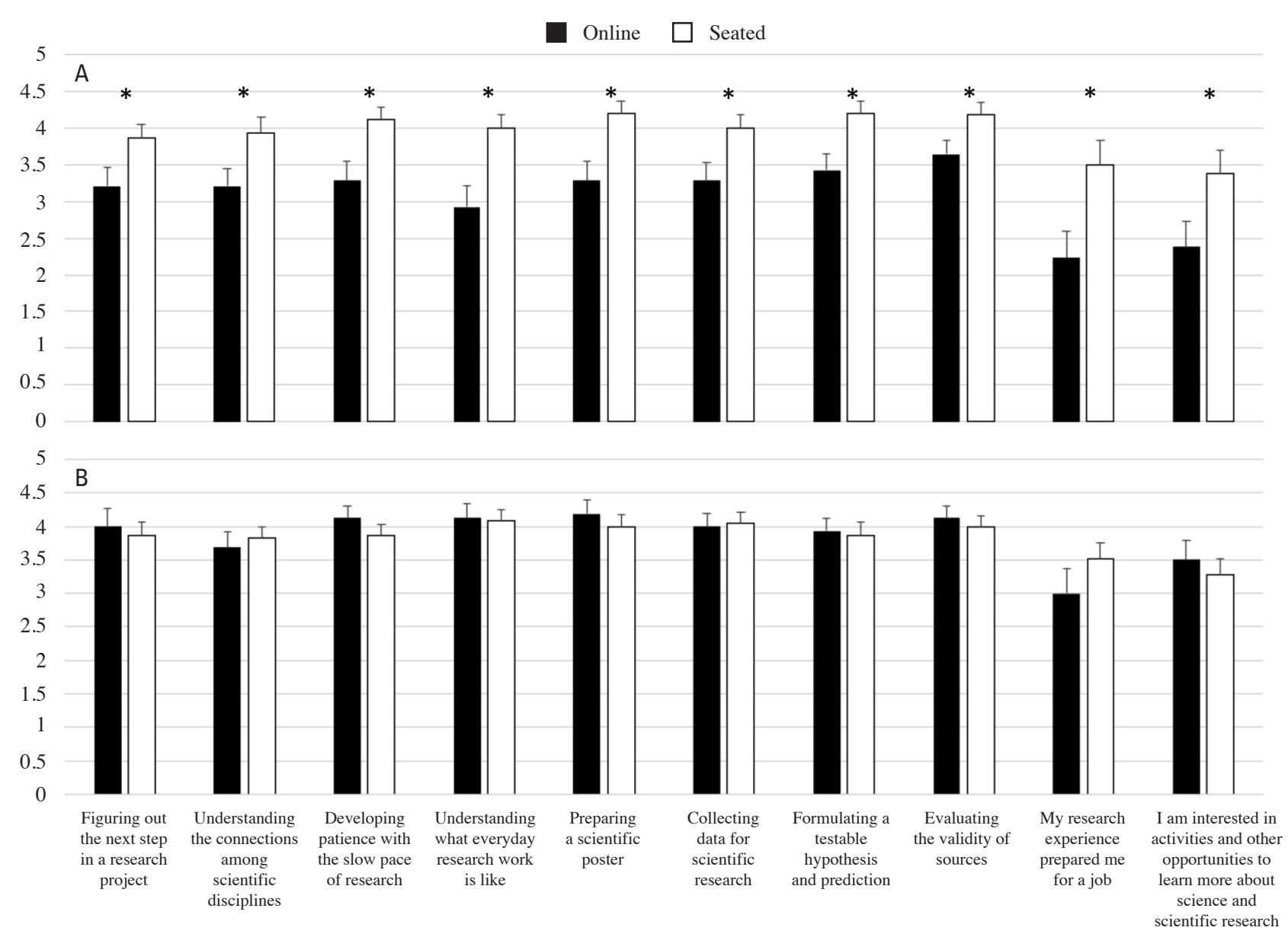

Note: URSSA = Undergraduate Research Student Self-Assessment; CURE = course-based undergraduate research experience. URSSA responses were based on a Likert scale ( $0=$ low, $5=$ high). Sample sizes were the following: spring 2019 (online $n=14$, seated $n=16$ ), spring 2020 (online $n=23$, seated $n=16$ ). Spring 2020 included the additional interventions integrated for online students.

*Significant differences between sections (two-sample $t$-test, $\alpha=0.05$ ). Complete post-project survey results can be obtained from the author.

As assessed by changes in student URSSA responses before and after the CURE, improvements in science literacy and evidence-based decision-making, attitudes toward science and research, and understanding of the role of research in education and career were present, yet not consistent. Gains were more prevalent for seated than online students in both 2019 and 2020. This is interesting, as there were no significant differences between seated and online students in their self-assessed confidence and proficiency at the end of the CURE in spring 2020. Students self-selected to enroll in the seated or online section of the course, and online students may already have had skills and experiences that were relevant and beneficial, such that gains over the duration of the CURE were lower than for the seated students. This leads to the next iteration of revisions and modifications to the CURE; assignment instructions and tasks will be modified to increase their effectiveness in improving outcomes for both seated and online students. All students consistently reported positive experiences with the CURE as well as the inherent complexity and value of the scientific process. When asked about the greatest benefit provided by the CURE, student responses were thoughtful and insightful. Several students recognized the relevance and value of the scientific process and its application to problem solving in other fields and reported an increased appreciation for environmental issues. Another theme that emerged from student responses was preparation for future courses and careers, and non-STEM majors gained confidence and felt much less intimidated by science.

Because the sample size for students who participated in this SoTL study was small (participation was voluntary), there is limited statistical power in the quantitative results. However, the greatest value of the results is that they qualitatively demonstrate that UR provides a meaningful experience that contributes to student engagement and success and that it is perceived as important for future educational and career goals. As such, it accomplishes the overall goal of the CURE, although the reflective and iterative process of evaluation and improvement will be 
continued in future terms. A limitation of this study is that the impact of the CURE on BIPOC, underresourced, and first-generation students cannot be parsed out; these data will be collected and analyzed in future studies. In a question integrated into the final exam at the end of each semester, students are asked for their views on the most memorable and impactful component of the course. The majority of students respond with a statement that references the CURE, what they learned, or how much they enjoyed participating as a citizen scientist for WildCam Gorongosa. Students clearly enjoy identifying pictures and investigating questions about African animals in an ecosystem unfamiliar and exotic to them.

Although WildCam Gorongosa represents one citizen science project available on Zooniverse, the structure for this CURE may easily be adapted and modified for other Zooniverse projects (e.g., Snapshot Safari, Eyes on the Wild) or a wide variety of other data sets that also are publicly available. Students in introductory, nonmajor courses with large class sizes and multiple delivery formats are very capable of learning and following the scientific process, but they benefit greatly when that process is thoroughly scaffolded and provides opportunities for assessment and feedback along the way. This "learning by doing" pedagogical model also can help reduce performance gaps between students from diverse backgrounds and experiences (e.g., Freeman et al. 2014) in addition to providing students with the opportunity to learn science actively by actually doing science. Guiding students through the CURE also offered the instructor the opportunity to work with students in small groups, which influenced and developed rapport and a positive learning environment in the classroom, even when that classroom was in a virtual space. In addition to small-group (rather than individual) mentoring by faculty, collaborative student-student interactions are another important component of CUREs (Bhattacharyya et al. 2020).

\section{Conclusions}

Iterative evaluation and improvement in how UR is integrated into the learning experiences of non-STEM majors in introductory courses across multiple delivery formats will contribute to the development of best practices for broadening participation in UR in a wider variety of courses and institutions and provide an inclusive and equitable experience for all students (Bangera and Brownell 2014; Staub et al. 2016). Although there are extensive examples of UR opportunities in STEM fields, introductory courses and non-STEM students also can benefit from these experiences (e.g., Bhattacharyya et al. 2020; Schuster 2018). Projects integrated into course curricula that are supported by institutional commitments to UR will ensure that UR continues to be a part of students' learning experiences. It is imperative that there is additional work focused on implementing and assessing UR experiences as well as sharing that information broadly, such that innovative solutions and best practices can be established for providing increased UR opportunities (Crowe and Brakke 2008). This study provides evidence that a CURE can be effectively implemented in large introductory courses offered both in person and online. Institutional structures that encourage and support the development and implementation of similar efforts will have a significant impact on broadening participation in UR by large numbers of students early in their undergraduate experiences.

\section{Acknowledgments}

The author thanks Catherine Ford and Megan Breit-Goodwin for support and guidance during the design and analysis phases of this SoTL project. Comments and feedback from Megan Breit-Goodwin, Margaret Guiney, Christina Holden-Sonnek, Rebecca Krystyniak, and Melissa Mills on previous versions of this manuscript were valuable and much appreciated.

\section{References}

Alkaher, Iris, and Erin L. Dolan. 2014. "Integrating Research into Undergraduate Courses: Current Practices and Future Directions." In Research Based Undergraduate Science Teaching, ed. Dennis W. Sunal, Cynthia Szymanski Sunal, Emmett L. Wright, Cheryl L. Mason, and Dean Zollman, 403-434. Research in Science Education, vol. 6. Charlotte, NC: Information Age.

Auchincloss, Lisa C., Sandra L. Laursen, Janet L. Branchaw, Kevin Eagan, Mark Graham, David I. Hanauer, and Gwendolyn Lawrie. 2014. "Assessment of Course-Based Undergraduate Research Experiences: A Meeting Report." CBE-Life Sciences Education 13: 29-40. doi: 10.1187/cbe.14-01-0004

Awong-Taylor, Judy, Allison D'Costa, Greta Giles, Tirza Leader, David Pursell, Clay Runck, and Thomas Mundie. 2016. "Undergraduate Research for All: Addressing the Elephant in the Room." CUR Quarterly 37(1): 11-19. doi: 10.18833/ curq/37/1/4

Ballen, Cissy J., Jessamina E. Blum, Sara Brownell, Sadie Herbert, James Hewlett, Joanna R. Klein, Erik A. McDonald, et al. 2017. "A Call to Develop Course-Based Undergraduate Research Experiences (CUREs) for Nonmajors Courses." CBE-Life Sciences Education 16(2): 1-7. doi: 10.1187/cbe.16-12-0352

Bangera, Gita, and Sara E. Brownell. 2014. "Course-Based Undergraduate Research Experiences Can Make Scientific Research More Inclusive." CBE-Life Sciences Education 13: 602-606. doi: 10.1187/cbe.14-06-0099

Bhattacharyya, Prajukti, Catherine W. M. Chan, and Meg Waraczynski. 2018. "How Novice Researchers See Themselves Grow." International Journal for the Scholarship of Teaching and Learning 12(2): ar 3. doi: 10.20429/ijsotl.2018.120203

Bhattacharyya, Prajukti, Catherine W. M. Chan, Rocio R. Duschesne, Aditi Ghosh, Steven N. Girard, and Jonah J. Ralston. 2020. "Course-Based Research: A Vehicle for Broadening Access to Undergraduate Research in the Twenty-First Century." Scholarship and Practice of Undergraduate Research 3(3): 14-27. doi: $10.18833 /$ spur/3/3/7 
Boyd, Mary K., and Jodi L. Wesemann (Eds.). 2009. Broadening Participation in Undergraduate Research: Fostering Excellence and Enhancing the Impact. Washington, DC: Council on Undergraduate Research.

Brandt, LaRoy S. E., and Jack L. Hayes. 2012. "Broader Impacts of Undergraduate Research at a Community College: Opening Doors to New Ideas." CUR Quarterly 33(1): 17-21.

Cejda, Brent D. 2009. "An Overview of Undergraduate Research in Community Colleges." In Undergraduate Research at Community Colleges, ed. Brent D. Cejda and Nancy Hensel, 1-7. Washington, DC: Council on Undergraduate Research.

Corwin, Lisa A., Mark J. Graham, and Erin L. Dolan. 2015. "Modeling Course-Based Undergraduate Research Experiences: An Agenda for Future Research and Evaluation." CBE-Life Sciences Education 14(1): es1. doi: 10.1187/cbe.14-10-0167.

Council on Undergraduate Research (CUR). n.d. "Our Organization." Accessed April 5, 2021. https://www.cur.org/who/ organization

Crowe, Mary, and David Brakke. 2008. "Assessing the Impacts of Undergraduate Research Experiences on Students: An Overview of Current Literature." CUR Quarterly 28(4): 43-50.

Freeman, Scott, Sarah L. Eddy, Miles McDonough, Michelle K. Smith, Nnadozie Okoroafor, Hannah Jordt, and Mary P. Wenderoth. 2014. "Active Learning Increases Student Performance in Science, Engineering, and Mathematics." Proceedings of the National Academy of Sciences 111: 8410-8415. doi: 10.1073/ pnas. 1319030111

Grabowski, Joseph J., Margaret E. Heely, and Jacob A. Brindley. 2008. "Scaffolding Faculty-Mentored Authentic Research Experiences for First-Year Students." CUR Quarterly 29(1): 41-47.

Hartline, Beverly K., and Muriel E. Poston. 2009. "The Mandate for Broadening Participation: Developing the Best Minds and Solutions." In Boyd and Wesemann 2009, 13-20.

Hensel, Nancy H., and Brian D. Cejda. 2014. Tapping the Potential of All: Undergraduate Research at Community Colleges. Washington, DC: Council on Undergraduate Research.

Higgins, Thomas B., Kenneth L. Brown, Jason G. Gillmore, Jeffrey B. Johnson, Graham F. Peaslee, and Daniel J. Stanford. 2011. "Successful Student Transitions from the Community College to the Four-Year College Facilitated by Undergraduate Research." CUR Quarterly 31(3): 16-22.

Howard Hughes Medical Institute (HHMI) BioInteractive. n.d. "Teaching Ecology Using Gorongosa National Park." Accessed April 5, 2021. https://www.biointeractive.org/planning-tools/ resource-playlists/teaching-ecology-using-gorongosa-national-park

Hunter, Anne-Barrie, Sandra L. Laursen, and Elaine Seymour. 2006. "Becoming a Scientist: The Role of Undergraduate Research in Students' Cognitive, Personal, and Professional Development." Science Education 91: 36-74. doi: 10.1002/ sce. 20173

Laursen, Sandra, Anne-Barrie Hunter, Elaine Seymour, Heather Thiry, and Ginger Melton. 2010. Undergraduate Research in the Sciences: Engaging Students in Real Science. San Francisco: Jossey-Bass.

20 Scholarship and Practice of Undergraduate Research
Linn, Marcia C., Erin Palmer, Anne Baranger, Elizabeth Gerard, and Elisa Stone. 2015. "Undergraduate Research Experiences: Impacts and Opportunities." Science 347: 627-633. doi: 10.1126/ science. 1261757

Lopatto, David. 2007. "Undergraduate Research Experiences Support Science Career Decisions and Active Learning." CBE-Life Sciences Education 6(4): 297-306. doi: 10.1187/cbe.07-06-0039

McKinney, Kathleen. 2006. "Attitudinal and Structural Factors Contributing to Challenges in the Work of the Scholarship of Teaching and Learning." Spec. issue, "Analyzing Faculty Work and Rewards: Using Boyer's Four Domains of Scholarship," ed. John M. Braxton, New Directions for Institutional Research, no. 129: 37-50. doi: 10.1002/ir.170

National Research Council (NRC). 2003. Improving Undergraduate Instruction in Science, Technology, Engineering, and Mathematics: Report of a Workshop. Washington, DC: National Academies Press.

National Student Clearinghouse (NSC) Research Center. 2017. "Two-Year Contributions to Four-Year Completions: 2017." Accessed April 5, 2021. https://nscresearchcenter.org/snapshotreport-twoyearcontributionfouryearcompletions 26

Osborn, Jeffrey M., and Kerry K. Karukstis. 2009. "The Benefits of Undergraduate Research, Scholarship, and Creative Activity." In Boyd and Wesemann 2009, 41-53.

Patton, Madeline, and Ellen Hause. 2020. Community College Undergraduate Research Experience Summit Proceedings Report. Washington, DC: American Association of Community Colleges. http://www.aacc.nche.edu/URESummit

Schinske, Jeffrey N., Virginia L. Balke, M. Gita Bangera, Kevin M. Bonney, Sara E. Brownell, Robert S. Carter, Douglas Curran-Everett, et al. 2017. "Broadening Participation in Biology Education Research: Engaging Community College Students and Faculty." CBE-Life Sciences Education 16(1): 1-11. doi: 10.1187/cbe.16-10-0289

Schuster, Matthew. 2018. "Undergraduate Research at Two-Year Colleges." Journal of Political Science Education 14: 276-280. doi: 10.1080/15512169.2017.1411273

Seymour, Elaine, Anne-Barrie Hunter, Sandra L. Laursen, and Tracee DeAntoni. 2004. "Establishing the Benefits of Research Experiences for Undergraduates in the Sciences: First Findings from a Three-Year Study." Science Education 88: 493-534. doi: $10.1002 /$ sce. 10131

Staub, Nancy L., Lawrence S. Blumer, Christopher W. Beck, Véronique A. Delesalle, Gerald D. Griffin, Robert B. Merritt, Bettye Sue Hennington, et al. 2016. "Course-Based Science Research Promotes Learning in Diverse Students at Diverse Institutions." CUR Quarterly 37(2): 36-46. doi: 10.18833/ curq/37/2/11

Weston, Timothy J., and Sandra L. Laursen. 2015. "The Undergraduate Research Student Self-Assessment (URSSA): Validation for Use in Program Evaluation." CBE-Life Sciences Education 14(3): ar33. doi: 10.1187/cbe.14-11-0206

Zooniverse. n.d. "WildCam Gorongosa." Accessed April 5, 2021. https://www.zooniverse.org/projects/zooniverse/wildcamgorongosa 


\section{Kristen S. Genet}

Anoka-Ramsey Community College,

kristen.genet@anokaramsey.edu

Kristen S. Genet has been a member of the biology faculty at Anoka-Ramsey Community College since 2003, teaching a wide variety of biology courses. Her areas of expertise are herpetology, ecology, and environmental biology, and for almost 10 years, she has been offering coursebased undergraduate research experiences (CUREs) and summer undergraduate research experiences (SUREs). She also has collaborated in designing a Biology Directed Research course; launching an Undergraduate Research, Scholarship, and Creative Activities (URSCA) team; and establishing an annual Outstanding Scholarship, Creative Activities and Research Symposium.

\section{NEW!}

\section{A Mathematician's Practical Guide to Mentoring Undergraduate Research is a} complete how-to manual on starting and nurturing an undergraduate research program in mathematical sciences. Readers will find advice on setting appropriate problems, directing student progress, managing group dynamics, obtaining external funding, publishing student results, and a myriad of other relevant issues.

Published by the American Mathematical Society and the Mathematical Association of America Press in cooperation with the Council on Undergraduate Research.

To order, visit the CUR Bookstore,

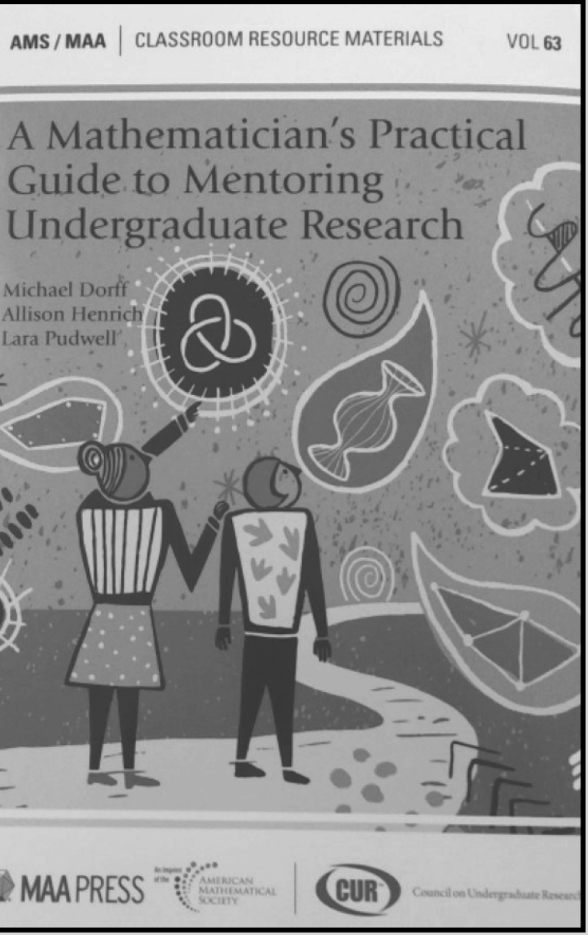
https://bit.ly/CURbkstore 